genuine enteric fever at all," while the former says that " had she been a patient of his he should not have hesitated to send her home, as in her condition he should not have apprehended any danger either to himself or to others." Their letters are given in full on pages 11, 12, 13, and 14 of the accompanying pamphlet.

I shall feel obliged by your inserting this correction in your next number.

I am, Sir, your obedient servant, G. F. MaberLY, M.R.C.S.

The Arboretum, Leamington, Nov. 23rd, 1872.

\section{REMOVAL OF CONVALESCENTS.}

To the Editor of THE LANCET.

F SIR,-In your notice of the case of Best $v$. Staff, you call attention to the statement at the trial that the children were removed by medical advice. I beg to say that my evidence was, that I distinctly objected to the removal so soon, and also expressly warned the mother of the danger of infecting other persons with whom they might be brought in contact. I am, Sir, yours truly,
N. H. ChIETON.

Cross-street, Islington, Nov, 24th, 1872.

** We gladly insert Mr. Clifton's letter. His conduct in this painful case seems to have been altogether right.ED. L.

\section{IRELAND.}

\section{(From our own Correspondent.)}

THe thirty-fifth annual meeting of the Dublin Obstetrical Society took place on Saturday, the 23rd November. An able address was delivered by the President, Dr. Kidd, in which he passed a high eulogium on two members of the Association recently deceased, Dr. Thomas F. Beatty and Sir James Simpson, and took occasion to defend the latiter from the attack of an anonymous writer which lately ap peared in the Edinburgh Medical Journal, alluding to anæsthetics, and to a statement recently made that a death occurs from chloroform weekly. He remarked that after strict inquiry he was able to discover but four deaths from chloroform in Dublin over a period of twenty-five years. Another death had occurred during an operation in which chloroform had been used, but it was to be attributed to the admission of air into the veins.

Dr. Evory Kennedy was elected president of the Society for the ensuing year.

It is believed by the profession in Dublin that a baronetey will be conferred on Dr. Kennedy at an early date. There are several other claimants for a similar honour, and certain lay papers expatiate on the virtues of some of the candidates in a manner suggestive of inspiration. A like exacerbation occurred about a year ago, which was much deprecated by the bulk of the profession, and greatly ridiculed by the public.

The prospectus of a medical fortnightly paper, to be called The Irish Hospital Gazette, is just issued. It will appear on January 1st, 1873, and will be devoted to hospital reports, pathological observations, original communications, abstracts of reports of societies, \&c. There is, no doubt, ample material for the production of such a journal in Ireland; but, owing perhaps to the fact that, with the ex. ception of Dublin, Belfast, and Cork, the hospitals in Ireland are so scattered, and it is so difficult to collect material, two series of hospital reports have already died of inanition.

The first case of superannuation under Sir Dominic Corrigan's Bill of last session took place in the Tralee Union last week. Dr. Fitzmaurice received $\$ 27$ 12s. 8d., being twothirds of his emoluments for registration and vaccination, or the average for three years ending 30th June, 1872, in addition to the sum of $\$ 66$ 13s. $4 d$., being two-thirds of his salary.

The Registrar-General, in his health report of Dublin for the week ending November 23rd, attributes one death to simple cholera. There was but one death from small-pox during the same week. The Small-pox Relief Association have bronght their labours to a close. During the epidemic they collected close upon $\$ 5000$, and assisted over 4000 families. The balance in hand, about $\$ 500$, they have distributed equally amongst the five hospitals which had received cases of small-pox. The cost per case to each hospital for small-pox has been estimated at $\& 3$. The number of cases treated in the Dublin Hospital was about 5000 .

The election for the Professorship of Physic at the Royal College of Surgeons will be held on the 3 rd Decem. ber. Six candidates are mentioned, of whom Dr. Samuel Gordon and Dr. Henry Kennedy are the seniors. Dr. McClintock, who has lately been seriously indisposed, is now convalescing.

Dublin, November, 1872

\section{PARIS.}

(From our own Correspondent.)

NoTwITHSTANDING the great political crisis through which the National Assembly is now going, the members thereof yet find time for, and can manage to give their attention to, the diseussion of questions of minor interest, but which are not the less of considerable importance, as they bear upon the public health. Yesterday the greater part of the séance was taken up by the discussion of an important measure of reform on the work of children in manufactories. M. Joubert, the promoter of the motion, very eloquently insisted on the necessity to society of "solid arms, honest hearts, and cultivated intellects"; the wants of industry should not exclude those of morals and intellectual cultivation; the workshop, the church, and the school should be equally taken into account, and the moral education of children as well as their physical development carefully looked after. To ensure these objects M. Joubert stated that the committee had fixed upon the age of ten years as the proper time for children to begin to work, and upon six hours as the daily space of time to be devoted to labour. Until the age of thirteen children are not to work more than six hours a day, and if at that age they have not attained the wonted degree of general knowledge, the space of six hours daily will be maintained till the age of sixteen. They are not to work during the night till the age of sixteen. Sundays and fête days are to be quite free from work. Furthermore, women and girls are to be excluded from all underground work, and from night labour in the workshops. Such are the chief features of the contemplated law, to secure the proper working of which local and general inspections (containing medical men) will be appointed.

M. Louis Blanc, in a few short remarks, did justice to the English, who had taken the lead in this question of humanity and self-preservation. $\mathrm{He}$ said that the law about to be adopted would be milder than the English one, since the terms were ten years instead of eight, and six hours instead of six and a half.

M. Tallon, the reporter, mentioned that at present, out of 125,000 children working in manufactories, 26,000 were not protected by the existing laws; whilst 26,000 are subjected to the bonds of apprenticeship and can get no education. He referred to the fact, that out of the 325,000 conscripts called out every year, 102,000 were sent back as unfit for military service, and that rachitism, which was so prevalent among them, was mainly due to premature and excessive work.

In a few months Dr. Bazin, the celebrated teacher of dermatology at the Hôpital St. Louis, whose writings on skin diseases are so universally known and appreciated, will have attained the limit of age fixed upon for retirement by the hospital regulations, and will be compelled to give up his clinique at St. Louis. His hospital colleagues and former pupils have initiated a subscription among the profession for the purpose of placing a bust of the Professor in the lecture-hall of St. Louis. The success of the subscription has been great-for this country at least, where such proceedings are exceedingly rare-and the lists are fast filling. It must be some consolation to M. Bazin on leaving office to see how highly popular and esteemed his name is among the profession.

Somewhat in connexion with the above subject, I may mention that the Société Médicale des Hôpitaux has roted 5000 francs at one of its last sittings for assistance 